\title{
O Caráter Contemporâneo da Língua Portuguesa no Universo Multilíngue de um Sujeito com Síndrome do X-Frágil
}

\author{
The Contemporary Portuguese Character in the Universe of A \\ Multilingual Subject with Fragile X Syndrome
}

\section{Isabela Barbosa do Rêgo Barros* Lorena Grace do Vale Deissler**}

Resumo: Associada muitas vezes ao autismo em virtude da similaridade dos sintomas (SCHWARTZMAN et al., 1995; DIAMENT; CYPEL, 1996), a Síndrome do X-Frágil (SXF) é caracterizada, sobretudo, por déficit cognitivo acompanhado por alterações comportamentais e sensório-motoras, distúrbio de aprendizagem, comprometimento físico e de linguagem. Esta é marcada por atraso em sua aquisição, omissões, substituições e distorções fonéticas, ecolalia, holofrase, frases curtas, pausas e hesitações, frequentes interjeições e monólogos. Este artigo objetiva discutir o caráter contemporâneo da língua portuguesa e o processo de identificação na linguagem em um contexto multilíngue como fundamentais para a apropriação de uma língua por um sujeito diagnosticado com SXF. Baseamos nossas discussões na Teoria da Enunciação de Émile Benveniste (2005, 2006) e nos estudos de Silva (2009), que analisa por uma perspectiva enunciativa a relação língua, linguagem e sujeito. Percebemos que a língua portuguesa foi utilizada em ocasiões específicas, marcando produções singulares em português, alemão clássico e

\footnotetext{
* Doutora em Letras pela Universidade Federal da Paraíba (2011). Professora Assistente III do Programa de Pós-Graduação em Ciências da Linguagem e do curso de Graduação em Letras da UNICAP. Contato: ibelabarros@gmail.com. ** Mestre em Ciências da Linguagem pela Universidade Católica de Pernambuco (2014). Contato: lorenagrace@hotmail.com.
} 
no dialeto alemão Schwäbisch como efeitos das operações do sujeito na linguagem, indicando que o ensino e a apropriação de uma língua se estabelece em uma relação de identificação com o sujeito que dela faz uso.

Palavras-chave: Língua Portuguesa. Contemporaneidade. Síndrome do XFrágil (SXF).

Abstract: Associated often in autism by virtue of the similarity of symptoms (SCHWARTZMAN et al., 1995; DIAMENT; CYPEL, 1996), Fragile X Syndrome (FXS) is characterized mainly by cognitive impairment accompanied by behavioral changes and sensorimotor, learning disability, physical impairment and language. This is marked by delay in its acquisition, omissions, substitutions and phonetic distortion, echolalia, holophrase, short sentences, pauses and hesitations, interjections and frequent monologues. This article aims to discuss the contemporary character of the Portuguese language and the identification process in the language in a multilingual context as key to the appropriation of a language by a subject diagnosed with FXS. We base our discussions on Enunciation theory of Emile Benveniste $(2005,2006)$ and studies of Silva (2009) which analyzes for a stated perspective regarding the language, language and subject. We realized that the Portuguese language was used on specific occasions, marking unique productions in Portuguese, classical German and German dialect Schwäbisch as effects of the operations of subject, indicating that education and ownership of a language is established in an identification relationship to the subject that makes use of it.

Keywords: Portuguese. Contemporaneity. Fragile X Syndrome (FXS).

\section{Introdução}

A Síndrome do X Frágil (SXF) foi descrita pela primeira vez pelos pesquisadores Martin e Bell, em 1943, após a observação de famílias em que alguns de seus membros do sexo masculino possuíam as mesmas características: déficit cognitivo, desordens comportamentais (hiperatividade e dificuldade de manter a atenção e a concentração), alterações físicas e sensório-motoras, distúrbio de aprendizagem e de linguagem (GIACHETI; COSTA; SPINELLI, 1992; SCHWARTZMAN et al., 1995; GUERREIRO, 
1998; BORTOLOTTO; FREIRE; SILVA, 2009; MOLINA; JUSTE; FUENTES, 2010; MONTENEGRO, 2011).

A literatura científica destaca como alteração na linguagem a lentidão ao emitir respostas, o que influencia no ritmo de aprendizagem e a necessidade do apoio visual para compreensão do enunciado. É consenso que as crianças com SXF apresentem problemas na recepção e expressão da linguagem, como concluem Giacheti, Costa e Spinelli (1992). Quanto à fala, os pesquisadores Hargeman e Hargeman (2002) destacam seu caráter peculiar, marcado pelas omissões, substituições e distorções fonéticas.

Fisch, Holden e Carpenter (1999) atestam que os sujeitos afetados pela SXF possuem severo atraso da fala e linguagem semelhante à idade cronológica de 48 meses. Desvio fonético, fonológico, ecolalia, frases curtas, pausas e hesitações, frequentes interjeições e monólogos delineiam, em geral, o quadro dos pacientes diagnosticados com a SXF.

Para além das dificuldades clínicas e linguísticas inerentes à síndrome, o sujeito deste estudo encontrava-se em um cenário multilíngue no qual a língua portuguesa correspondia àquela do país natal da criança e de sua mãe; o alemão clássico (Hochdeutsch) correspondia à língua oficial do país residente, sendo ensinada na escola; e o Schwäbisch era apenas um dos diversos dialetos falados pelos habitantes da região sudoeste da Alemanha, local da residência da criança, e eleito e falado pelos avós adotivos paternos.

A criança imigrou para Alemanha aos quatro anos de idade, após o segundo casamento materno, ocasião em que foi diagnosticada com a Síndrome do X-Frágil. A linguagem da criança caracterizava-se, sobretudo, por pouco vocabulário, imprecisão articulatória, gesticulação e holofrase ${ }^{1}$. Para surpresa dos familiares, a criança rapidamente enunciou suas primeiras palavras em Schwäbisch e não falava a língua alemã clássica, que era ensinada oficialmente nas escolas. $\mathrm{Na}$ época do estudo, a criança tinha onze anos de idade e morava numa vila alemã com sua mãe brasileira, pai e avós adotivos alemães.

${ }^{1} \mathrm{O}$ conceito de holofrase vem sendo construído desde que foi mencionado pela primeira vez, na década de 1970, até os dias de hoje; no geral, refere-se "ao uso, pela criança, de enunciados de uma palavra para expressar uma ideia complexa, especificamente uma oração ou uma proposição" (SCARPA, p. 1, 2009). 
O caráter contemporâneo da língua portuguesa aponta para sua coexistência com diversas outras línguas no cenário multifacetado da linguagem, sem que seu lugar se perca ou se confunda para o sujeito que a toma como espaço de enunciação. Benveniste (2006) informa que, através do ato enunciativo, o sujeito se apropria das unidades semióticas disponíveis nas línguas, concomitantemente as atualizam no discurso e as coloca em funcionamento de modo correlacional.

A proposta do artigo é discutir o caráter contemporâneo da língua portuguesa e o processo de identificação na linguagem em um contexto multilíngue como fundamentais para a apropriação de uma língua por um sujeito diagnosticado com SXF. Não obstante, procuramos perceber os deslocamentos linguísticos da criança que deixa seu país de origem, o Brasil, e mergulha noutra realidade linguística que, diferente daquela que foi seu berço, apresenta algumas particularidades em meio à pluralidade linguística e cultural brasileira e europeia.

Nossa discussão circunscreve os aspectos de que o uso e a aprendizagem de uma língua são atravessados por uma relação de identificação linguística, o que implica ser a língua constitutiva do sujeito e não algo exterior, o que torna contraditório a escola considerar que o ensino padrão de línguas (materna ou estrangeira) deve ser imposto ao sujeito como um elemento distante do universo subjetivo.

Para Saussure (2012, p. 253), o que "surpreende no estudo das línguas é sua diversidade, as diferenças linguísticas que se apresentam quando se passa de um país a outro, ou mesmo de um distrito a outro”. Para o autor, essa diversidade se dá não apenas ao fator tempo, mas também ao espaço, o que torna indispensável para tomada de consciência do falante de sua própria língua. Somos levados instintivamente a fazer analogias entre idiomas quando damos conta de que existem outras línguas diferentes da nossa, mesmo que aparentemente possuam parentesco que refletem traços próprios da comunidade.

Saussure (2012) informa que dois idiomas podem divergir entre si por pequeno grau, o que ele chamou de dialetos, diferindo da língua apenas pela quantidade, mas não pela natureza, podendo inclusive coexistir lado a lado num mesmo lugar, sem se confundirem. Segundo o estudioso, a superposição de línguas deve-se ao movimento de invasão de povos, ou colonização, 
nomadismo, e demais penetrações pacíficas que trazem consigo, dentre outras bagagens, a sua linguagem.

\section{Língua, Fala e Linguagem}

Não podemos mencionar a língua sem recorrermos aos estudos de Saussure, presentes no Curso de Linguística Geral (CLG), obra póstuma, publicada por alguns de seus discípulos em 1916. Em seus cursos, Saussure foi sucinto ao afirmar que o estudo da linguagem como fato humano está inteiramente ou quase inteiramente contido dentro do estudo das línguas. Os fenômenos da linguagem mais elementares nunca serão percebidos e compreendidos sem que se recorra, nas instâncias inicial e final, ao estudo das línguas, posto que “é necessário colocar-se primeiramente no terreno da língua e tomá-la como norma de todas as outras manifestações da linguagem" (SAUSSURE, 2012, p. 16). Incluem-se entre essas manifestações os gestos, o silêncio, os desenhos, sinais de trânsito, olhares, dança, bem como outras formas de linguagem.

Esse olhar para a linguagem como um objeto unido à língua (lado social) e à fala (lado individual) é perpetuado em diferentes leituras da obra de Saussure, assim como a separação que o autor faz entre língua e fala. Lopes (1997) percebe nos trabalhos semióticos de Saussure a presença de duas perspectivas voltadas para a análise dos fenômenos da linguagem: a perspectiva sintética e a perspectiva analítica, que não são isoladas uma da outra pelo julgo do autor: "o mecanismo linguístico gira todo ele sobre identidades [perspectiva sintética] e diferenças [perspectiva analítica], não sendo estas mais que a contraparte daquelas" (SAUSSURE, 2012, p. 126).

Em registro apoiado nos estudos que fez a respeito dos ensinamentos de Saussure, Lopes (1997) admite que o autor genebrino possuía uma percepção sintética dos fenômenos linguísticos, ao referir-se à linguagem como uma totalidade constituída a partir da conjunção de partes que lhe conferem uma identidade. $\mathrm{O}$ que pode ser confirmado na passagem a seguir, retirada do CLG:

Evitando estéreis definições de termos, distinguimos primeiramente, no seio do fenômeno total que representa a linguagem, dois fatores: 
a língua e a fala. A língua é para nós a linguagem menos a fala. (SAUSSURE, 2012, p. 92, grifo nosso).

A perspectiva analítica é aquela que destaca as diferenças dos elementos língua, fala e linguagem:

Mas o que é a língua? Para nós, ela não se confunde com a linguagem; é somente uma parte determinada, essencial dela, indubitavelmente. É, ao mesmo tempo, um produto social da faculdade de linguagem e um conjunto de convenções necessárias, adotadas pelo corpo social para permitir o exercício dessa faculdade nos indivíduos. (SAUSSURE, 2012, p. 17)

A fala é, ao contrário, um ato individual de vontade e inteligência, no qual convém distinguir: $1^{\circ}$, as combinações pelas quais o falante realiza o código da língua no propósito de exprimir seu pensamento pessoal; $2^{\circ}$, o mecanismo psico-físico que lhe permite exteriorizar essas combinações. (SAUSSURE, 2012, p. 22).

Podemos afirmar, portanto, que a língua e a fala pertencem e formam a linguagem, que só existe e subsiste porque há língua e fala que a torna presente. "Não é, então, ilusório dizer que é a língua que faz a unidade da linguagem" (SAUSSURE, 2012, p. 18).

Saussure, no capítulo do CLG intitulado "Linguística da língua e linguística da fala”, nos revela que há uma necessidade mútua entre língua e fala no sentido de suas existências.

O estudo da linguagem comporta, portanto, duas partes: uma, essencial, tem por objeto a língua, que é social em sua essência e independente do indivíduo; esse estudo é unicamente psíquico; outra, secundária, tem por objeto a parte individual da linguagem, vale dizer, a fala, inclusive a fonação e é psico-física.

Sem dúvida, esses dois objetos estão estreitamente ligados e se implicam mutuamente; a língua é necessária para que a fala seja inteligível e produza todos os seus efeitos; mas esta é necessária para que a língua 
se estabeleça; historicamente, o fato da fala vem sempre antes. [...] Existe, pois, interdependência da língua e da fala; aquela é ao mesmo tempo o instrumento e o produto desta. Tudo isso, porém, não impede que sejam duas coisas absolutamente distintas. (SAUSSURE, 2012 , p. 27 , grifo nosso).

A separação característica do olhar de Saussure, que Lopes (1997) nomeou como perspectiva analítica, responsável por esmiuçar cada parte constituinte na formação de um todo, permite que hoje tenhamos a possibilidade de discutir a condição de língua como objeto de apropriação de uma criança com a Síndrome do X-Frágil que, no universo multilíngue, enuncia-se e constitui-se como sujeito em um processo de identificação com a língua.

Leffa e Irala (2014), refletindo sobre as implicações metodológicas para sala de aula, questionam se, no caso do ensino de outra língua, diferente daquela de origem, não seria preciso entender, também, até que ponto o sistema da outra língua se distancia ou se aproxima do já conhecido ou se a nova língua constituirá outro sujeito ao lado do que já existe ou adicionará uma nova identidade ao sujeito.

\section{Língua Materna e Estrangeira}

Apesar da terminologia Língua Materna (LM) remeter aos conceitos de língua nacional, língua da mãe, algo memorizado, não é tão fácil explicar a noção de LM, haja vista que nem todas as crianças nascem num país onde a língua social é a língua materna dos seus pais (SILVA, 2012). Além dessa questão, sabemos que existem países bilíngues, dentre outras situações como filhos de imigrantes e nômades. Portanto, a denominação "materna" atribuída à língua é apenas uma alusão incerta e distante, determinada pelos vestígios obsoletos da relação linguística com a mãe (JERUSALINSKY, 2008).

Assim, vemos que a LM não é "materna” no sentido usual do termo, pois há sentidos interditados, sentidos inscritos no inconsciente. A LM, segundo Fink (1998), é exatamente aquela da constituição do sujeito, que verdadeiramente funda o sujeito. Ela estabelece a relação com a língua estrangeira, no entanto, constrói-se uma ilusão de monolíngua absoluta, 
transparente, que só existiria como construção imaginária, pois as irrupções esporádicas no fio do discurso resvalam inconscientemente à heterogeneidade do enunciador.

A língua estrangeira, segundo Leffa e Irala (2014), é aquela não falada na comunidade, distante do universo do sujeito, diferente do termo segunda língua, referente ao sistema falado na comunidade, que não representa, porém, a língua oficial do país.

Para Moraes (1999), LM não é a mesma que a língua nacional, não aquela que pertence à mãe, mas aquela que inscreve o sujeito na/pela linguagem. A autora diz ainda que "é sobre a escrita da LM que as outras línguas se arranjam” (MORAES, 1999, p. 126). Sob essa ótica, a LM pode ser considerada como "responsável por inaugurar a passagem para demais línguas" (BRAZÃO, 2010, p. 71).

Para Melman (1992), saber uma língua materna é ser falado por ela, isso indica que "conhecer" e "saber" uma língua são movimentos distintos. Ultrapassando essas considerações para o ensino de línguas (nacional ou estrangeira), acreditamos que o aprender uma língua fundamentada no preceito do saber obedece a um processo de reconhecimento de si como sujeito permeado e constituído pela língua, enquanto o aprender baseado no conhecimento linguístico funda-se na distância entre o sujeito e o objeto do conhecimento: a língua.

Leffa e Irala (2014) endossam os achados de Moraes (1999) e afirmam que o sistema de outra língua, incorporando o léxico e a sintaxe, é construído sobre a língua já conhecida, às vezes estabelecendo contrastes entre elas, mas, sobretudo, sugerindo uma convivência pacífica entre as línguas. "Funciona numa espécie de distribuição complementar com a língua materna, que será (ou não), preferencialmente usada em outros contextos (na vida familiar, com os amigos, nos serviços públicos)". (LEFFA; IRALA, 2014, p. 33).

Podemos dizer que a língua materna é única, inesquecível, nunca silenciada, ela transparece na superfície da fala, mesmo quando uma língua estrangeira é falada. Concordamos com Melman (1992, p. 70) quando diz que a "língua materna é a língua que interdita e imaginariza a mãe, é a língua do desejo". Para o psicanalista francês, "essa língua chamada 'materna' pode não ser a da mãe, a língua 'estrangeira' pode até ser familiar, mas elas não serão jamais da mesma ordem” (MELMAN, 1992, p. 215). 
Diante da diversidade das línguas e da força dos efeitos do tempo e do espaço que influenciam na sua evolução, centramos o artigo na perspectiva do usuário da língua portuguesa, no que acontece com a relação sujeitolíngua imerso no ambiente entre línguas, que se constitui nesse interstício, nesse entremeio.

Tomamos a língua enquanto materialidade, considerando que a possibilidade de deslize ou equívoco são intrínsecos à sua estrutura, sempre falho, permite deslizes do sujeito. Propomos aqui pensar a relação do sujeito nas línguas, inserida num contexto de imigração, levando em consideração a constituição híbrida, heterogênea e conflituosa de identidade, lembrando que o sujeito não é qualquer falante, mas é um sujeito que enuncia do lugar entre-línguas, que tem diagnóstico de SXF e, portanto, é um sujeito marcado por deslocamentos, estranhamentos, encontros e desencontros na língua.

\section{Recorte Enunciativo 1:}

Contexto: A criança, a mãe e a amiga brasileira estavam a caminho de uma clínica para tratamento fisioterápico.

\begin{tabular}{|l|l|l|l|l|}
\hline & $\begin{array}{c}\text { Amiga materna } \\
\text { brasileira }\end{array}$ & Mãe & Criança & \multicolumn{1}{c|}{$\begin{array}{c}\text { Cena } \\
\text { enunciativa }\end{array}$} \\
\hline 1 & & & $\begin{array}{l}\text { Was machst Du? } \\
\text { (O que você } \\
\text { faz? })\end{array}$ & $\begin{array}{l}\text { A criança } \\
\text { pergunta à } \\
\text { amiga materna o } \\
\text { que ela estava } \\
\text { fazendo. }\end{array}$ \\
\hline 2 & $\begin{array}{l}\text { Nada. E você? } \\
\text { O que você está } \\
\text { fazendo? }\end{array}$ & & $\begin{array}{l}\text { Ela entende o } \\
\text { enunciado e } \\
\text { responde em } \\
\text { português. }\end{array}$ \\
\hline 3 & & & $\begin{array}{l}\text { A criança não } \\
\text { responde e } \\
\text { muda o olhar } \\
\text { para outra } \\
\text { direção. }\end{array}$ \\
\hline 4 & Você está bem? & $\begin{array}{l}\text { A mãe se dirige } \\
\text { para a amiga } \\
\text { utilizando a } \\
\text { língua } \\
\text { portuguesa. }\end{array}$ \\
\hline
\end{tabular}




\begin{tabular}{|l|l|l|l|l|}
\hline 5 & $\begin{array}{l}\text { Não, estou } \\
\text { tonta. }\end{array}$ & & $\begin{array}{l}\text { Naja } \\
\text { (Ah sim) }\end{array}$ & $\begin{array}{l}\text { A criança olha } \\
\text { para a amiga. }\end{array}$ \\
\hline 6 & & $\begin{array}{l}\text { O que foi que } \\
\text { aconteceu? Você } \\
\text { está bem? }\end{array}$ & $\begin{array}{l}\text { A amiga feriu } \\
\text { seu polegar na } \\
\text { porta do carro. }\end{array}$ \\
\hline 7 & & & $\begin{array}{l}\text { A amiga não } \\
\text { responde à mãe } \\
\text { da criança. }\end{array}$ \\
\hline 8 & Ai! & & $\begin{array}{l}\text { A criança } \\
\text { responde. }\end{array}$ \\
\hline 9 & & & $\begin{array}{l}\text { Nein, tonto. } \\
\text { Não, tonto. }\end{array}$ \\
\hline
\end{tabular}

Nesse recorte, o lugar ocupado pela língua portuguesa no ambiente plural confunde-se com as outras línguas, nas quais a criança se enuncia, campo de constituição do sujeito. Benveniste (2005) menciona que é na relação subjetiva entre o "eu” e o "tu" que o sujeito se estabelece: "É na linguagem e pela linguagem que o homem se constitui como sujeito; porque só a linguagem fundamenta na realidade, na sua realidade que é a do ser, o conceito de "ego" (BENVENISTE, 2005, p. 286). A criança, apesar de inicialmente negar-se ao encontro com a língua portuguesa, mudando a direção do olhar (linha 3), identifica-se posteriormente com seu interlocutor (amiga materna) e lhe é solidário ao utilizar a língua portuguesa (linha 9), uma vez que o outro tinha como campo enunciativo a língua do seu país de origem: o Brasil.

Entendemos que a fala da criança não fora mera repetição do discurso do interlocutor, pois ela alterou o gênero da palavra 'tonto', diferente da forma apresentada anteriormente 'tonta' e utilizou palavra 'nein' (não) em alemão clássico ensinado na escola, o que indica o conflito babélico do estar entre-línguas. Desse modo, o enunciado infantil não é percebido como uma ecolalia, repetição aleatória de uma palavra ou trecho do discurso de outrem, contrariando os informes médicos que destacam sua presença na linguagem da criança com SXF.

Para Lier-DeVitto (2005) as composições paralelísticas e repetições remetem, por definição, a um sistema de "correspondências" de construções sintáticas, combinações sonoras e de esquemas prosódicos, que são transformados em significantes em "eco", abrindo espaço para o equívoco, 
deixando mover o corpo da fala na voz da criança e que dizem respeito à sua instância subjetiva. Nesse alinhavo móvel de repetições, paralelismo, evasões e deslizamentos montam e desmontam enunciados e revelam que a criança, portanto, é falada pela língua, ou melhor, na substância material da fala é impregnada de carga subjetiva, como diz Lier-DeVitto (2005), aquilo que a ciência persegue (a forma correta) se realiza sob o custo da manutenção da dicotomia entre língua/fala.

Ao utilizar 'Nein, tonto. Não, tonto.' (linha 9), a criança se enunciou fazendo uso de dois sistemas linguísticos e, ainda, transcendeu o sentido da palavra tonto, pois a ressignificou a partir de um possível lugar de desconforto provocado pela língua.

A inscrição do sujeito na língua portuguesa causa estranhamento entre o conhecido e o familiar, que ao mesmo tempo afeta e incomoda. Afinal, a língua portuguesa é aquela que traz lembranças e retoma o passado infantil no Brasil, provocando efeitos e constituindo identidade.

Sob a perspectiva de Benveniste (2006), no texto "O aparelho formal da enunciação", publicado em 1970 na revista Langages e presente na obra Problemas de Linguística Geral II, o que caracteriza a enunciação é a acentuada relação discursiva com o parceiro, seja este real ou imaginário, individual ou coletivo. A presença da amiga, falante da língua portuguesa, parece provocar alterações no discurso da criança, e isso nos faz comprovar sua inserção na relação discursiva com o outro. A contradição na escolha de palavras põe em questão a contradição inerente à sua subjetividade, o que acaba por denunciar que o sujeito está no entre-lugar, no entre-línguas.

De acordo com Eckert-Hoff e Coracini (2010), esses efeitos contraditórios, vestígios de encontros e desencontros, certamente provocam a emergência de sentidos marcados pela inscrição na/pela língua portuguesa. O estranhamento é comum ao processo de reinvenção de uma nova língua, pois, embora imerso numa língua desconhecida, há sempre um conflito, um desconforto já que a língua portuguesa herdada de sua mãe não teimava em silenciar. A criança faz soar no alemão a língua que não se cala (a portuguesa), por mais que imite prosódia, que mude o ritmo, que respire diferente, o português ainda ecoa.

A relação do sujeito com a Língua Materna é modificada conforme o movimento das matrizes identificatórias e, provavelmente, não é o mesmo 
após relação de contraposição e interdição pela Língua Estrangeira. A identificação na e pela língua alude à constituição do sujeito na e pela linguagem.

Segundo Derrida (2001), não há puramente língua materna, pois não há língua que se possa habitar, nem mesmo que seja natural ou própria. $\mathrm{Na}$ perspectiva do autor, a relação do sujeito com a língua é sempre conflituosa, na medida em que causa constante estranhamento, seja numa "língua materna" ou noutra "estrangeira". O processo de "vir a ser falante" é doloroso e deixa marcas na linguagem.

A apropriação de uma língua, sendo ela estrangeira, segundo Vereza (2002), passa pela relação do indivíduo com a língua materna, porém, “essa mútua apropriação, ou seja, o processo por meio do qual o sujeito apropria-se de sua língua e por ela é apropriado, implica inevitavelmente construção de subjetividade ou identidade” (p. 352). Logo, a aprendizagem de uma língua envolve a aquisição ou reconfiguração de identidade.

\section{Língua Portuguesa, Identidade e Contemporaneidade}

Língua oficial em oito países (Angola, Brasil, Cabo Verde, Guiné Bissau, Moçambique, Portugal, São Tomé e Príncipe e Timor Leste) de quatro continentes, a língua portuguesa é a oitava língua mais falada no mundo e a terceira entre as línguas ocidentais, após o inglês e o espanhol.

O tema contemporaneidade na língua portuguesa remete à dinamicidade do objeto que está em constate correlação com outras línguas nos diferentes aspectos: sociocultural, político, econômico e geográfico, e o consequente impacto provocado na constituição da identidade linguística dos sujeitos.

É nos sujeitos que, ao dizer suas estranhezas sobre a realidade, segundo Dantas (2012), a contemporaneidade se encontra numa pesquisa sobre línguas. "A contemporaneidade invade os sujeitos em todas as suas atividades e, sobremaneira, naquelas de natureza simbólica e relacionadas à linguagem" (DANTAS, 2012, p. 19).

Para Benveniste (2006), adquirir a linguagem é se constituir como sujeito. Esclarecemos que a noção que adotamos de sujeito não é a do sujeito psicológico, nem do sociológico, tampouco do biológico; é a do sujeito que se constitui na/pela linguagem, aquele que está no próprio exercício da língua, que habita a linguagem, tornando-se efeito dela. 
A expressão sujeito na linguagem, sujeito pela linguagem, utilizada por Benveniste no texto "Da subjetividade na linguagem", de $1958^{2}$, referindose à constituição do sujeito, significa que o sujeito se torna presente na linguagem e por suas mãos, porque só esta fundamenta o conceito de ego. Em outras palavras, esse é habitado e habita na linguagem, por estar imerso na língua e fazer uso da fala para emergir.

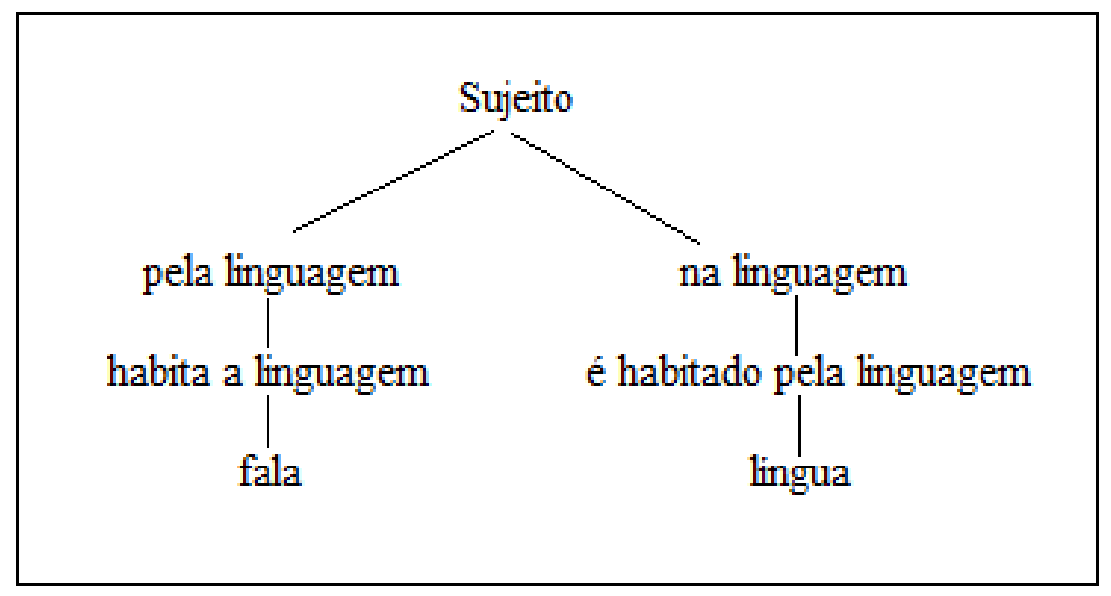

Figura 1: Lugar ocupado pelo sujeito

Posto dessa forma, a condição de sujeito se constitui de maneira simultânea no terreno da linguagem, como a ilustração acima tenta expor. Ao mesmo tempo em que é na linguagem - por meio de sua parte social, a língua - que o verbo faz o homem, uma vez que, antes mesmo do seu nascimento físico o sujeito já é falado por outros homens, é habitado por significantes exteriores. $\mathrm{O}$ sujeito se constitui pela linguagem, se impõe e se expõe ao fazer uso da língua por meio da fala ou ao fazer uso de outros sinais (gestos, expressões corporais, figuras...) e firma sua presença, habita a linguagem, tornando-se efeito dela.

${ }^{2}$ Presente na obra Problemas de Lingüistica Geral I (BENVENISTE, 2005). 
Concebemos a noção de sujeito tal como Benveniste (2005) desenha, aquele marcado pela presença da língua, fundado simbolicamente na/pela linguagem, aquele que se torna sujeito à medida que fala. O sistema no qual os termos se correlacionam engrenam o mecanismo de movimentação da língua. Não há o sujeito centrado, dono de seu dizer e produtor de verdades. Há o vir a ser sujeito a partir de uma relação intersubjetiva constitutiva, igualmente, de identidade.

A identidade, segundo Hall (1992), não é fixa no tempo, nem estática, muito menos inata. $\mathrm{O}$ autor sugere falar de identificação, ao invés de identidade, onde o termo implica algo inacabado, em eterno movimento, "um processo em andamento". Para ele,

... a identificação surge não tanto da plenitude da identidade que já está dentro de nós como indivíduos, mas de uma falta de inteireza que é 'preenchida' a partir do nosso exterior, pelas formas através das quais nós imaginamos ser vistos por outros. (HALL, 1992, p. 39, grifo do original).

Ou seja, a identificação é de cunho imaginário e fundamenta o reconhecimento do sujeito a partir das imagens que ele faz de si próprias direcionadas pelo olhar do outro. O sujeito se reconhece nas múltiplas identidades que ocupa em diferentes posições discursivas temporárias. A pluralidade dos cenários linguísticos e cultural influencia diretamente na produção de sentidos e valores de diferentes grupos na dinâmica das relações sociais.

Segundo Authier-Revuz (1998), o processo de construção de identidade passa necessariamente pela língua, onde acontece o reencontro do sujeito com sua própria língua materna. O material indissociável aos sujeitos é a língua, portanto, o que nos leva a crer que tanto a inscrição do enunciador na língua quanto as marcas da língua no enunciador é fundamental para a constituição identitária do sujeito.

O processo de identificação na(s)/pela(s) língua(s) é atravessado por algo que faz com que a preferência do sujeito seja por uma ou outra língua, mesmo diante das circunstâncias que forçam a inscrição do sujeito noutra língua, a exemplo do que ocorreu com a criança deste estudo ao ser submetida 
ao ensino institucionalizado dos padrões linguísticos do alemão clássico, porém mantém coexistindo a língua portuguesa e o dialeto $S$ chwäbisch.

Recorte Enunciativo 2:

Contexto: Mãe e filho estavam preparando a mesa para o jantar.

\begin{tabular}{|l|l|l|l|}
\hline \multicolumn{1}{|c|}{ Mãe } & \multicolumn{1}{|c|}{ Criança } & \multicolumn{1}{c|}{ Cena enunciativa } \\
\hline 1 & $\begin{array}{l}\text { João }{ }^{3} \text { o papi ajudou você } \\
\text { na tarefinha hoje? }\end{array}$ & $\begin{array}{l}\text { A mãe acaricia os } \\
\text { cabelos do filho. }\end{array}$ \\
\hline 2 & & $\begin{array}{l}\text { Ja, inha inha. } \\
\text { (Sim, 'inha') }\end{array}$ & $\begin{array}{l}\text { João responde com voz } \\
\text { aguda e melódica. }\end{array}$ \\
\hline 3 & Que bom! Terminou tudo? & & A mãe o coloca no colo. \\
\hline 4 & & $\begin{array}{l}\text { Ja. } \\
(\mathrm{Sim})\end{array}$ & $\begin{array}{l}\text { João fez gesto com } \\
\text { lábios, arqueando-os } \\
\text { para baixo. }\end{array}$ \\
\hline
\end{tabular}

Percebemos, nas linhas 2 e 4, que a criança se enuncia em dialeto Schwäbisch e alemão clássico (Hochdeutsch), posto que o termo 'ja' é equivalente nos dois sistemas linguísticos. O curioso é que a interlocutora (mãe) inicia o diálogo em português e a criança responde apenas parte em português: 'inha', utilizando o sufixo da palavra 'tarefinha', que não existe nas demais línguas em que está inserida. Como afirmou Benveniste (2005, p. 289), “a linguagem é, pois, a possibilidade da subjetividade, pelo fato de conter sempre as formas lingüísticas apropriadas à sua expressão; e o discurso provoca a emergência da subjetividade, pelo fato de consistir de instâncias discretas".

Uma análise pautada apenas no 'erro' e 'acerto' talvez destacasse no trecho 'inha' uma ecolalia resultante do sufixo presente em 'tarefinha'. No entanto, a mãe, na posição de interlocutora da criança, percebe o segmento como uma resposta e viabilidade para continuar o diálogo, o que poderia indicar um possível entendimento do trecho como uma apropriação da língua portuguesa pelo locutor ${ }^{4}$, resultante da segmentação da palavra original. É no

${ }^{3}$ Nome fictício utilizado para salvaguardar a identidade da criança.

${ }^{4}$ Em Benveniste, a noção de locutor é fundamental para a formulação da noção de sujeito. Locutor é o indivíduo linguístico marcado na língua no instante em que toma a palavra (FLORES, 2009). 
lugar da incompletude que a língua portuguesa resiste no universo multilíngue da criança. "O equívoco habita a língua, de modo que ela dispõe de um sistema, mas com buracos, por onde passam sentidos não desejados pela gramática e pelos dicionários" (DANTAS, 2012, p. 29).

Independentemente da presença da SXF, admitimos aqui que o sentido da linguagem reside na relação entre os significantes da criança e do adulto dentro de um espaço discursivo e essa concepção expande as possibilidades de análise quanto aos pormenores que acontecem na relação do sujeito com outros num cenário multilíngue.

É na instância de discurso na qual $e$ designa o locutor que este se enuncia como ‘sujeito'. É portanto verdade ao pé da letra que o funcionamento da subjetividade está no exercício da língua. Se quisermos refletir bem sobre isso, veremos que não há outro testemunho objetivo da identidade do sujeito que não seja o que ele dá assim, ele mesmo sobre si mesmo. (BENVENISTE, 2005, p. 288, grifo do autor).

Assim, acreditamos que a identidade do sujeito é constituída essencialmente como produto da relação de ser/estar entre línguas e culturas. A captura ou fuga ${ }^{5}$ do sujeito pela relação com a língua deixa rastros das vivências e andanças, mas sempre pela relação com o outro. A metamorfose que ocorre no processo de subjetivação se dá pela estranheza ou familiaridade no contato com a língua do outro, quer seja ela materna ou estrangeira. Afinal, a relação com o outro é determinada pelo ato enunciativo e é nele que se sustentam as posições dos sujeitos.

A identificação dos enunciadores com a língua passa por uma relação política entre homens, ou seja, o enunciador irá reconhecer seu próprio corpo, seu desejo e sua língua por intermédio do outro (UYENO; CAVALLARI, 2011). No entanto, Goldgrub (2008) afirma que a identificação ao outro, não confere ao meio um papel decisivo, pois o outro responsável pela identificação

${ }^{5}$ Captura e fuga foram termos inseridos na psicanálise que remetem à passividade do sujeito frente ao fenômeno da língua. 
atua com suas funções como portador do desejo graças ao qual o infans existe.

O conflito entre papéis parentais parece ser permanente na vida de quem abandonou a terra natal. Portanto, existe uma comunidade de origem ligada a determinada LM, de uma estrutura fundante do sujeito singular, o qual vê sua estrutura abalada em função do exílio. Esse movimento parece modificar consideravelmente a relação do sujeito em exílio com a língua. O sujeito multilíngue se enuncia num cenário de conflitos locais, sofre efeito da globalização, resulta de desvios de identidade, pois o encontro do sujeito com o estrangeiro produz um tipo de reconstrução da relação imaginária experimentada pelo sujeito. Contudo, no cenário multilíngue resulta da constante oposição de referenciais culturais, sociais e históricos do qual o sujeito está imerso.

O sujeito multilíngue é aquele com habilidades em usar mais de duas línguas, podendo ter mais fluência em uma que em outra ou desempenhos diferentes em função do contexto de uso e do propósito comunicativo (ZIMMER; FINGER; SCHERER, 2008).

Considerando os aspectos da linguagem envoltos na subjetividade, acreditamos num conceito de multilinguismo que destaca a dinamicidade da enunciação. Entendemos, pois, o sujeito multilíngue como aquele que se enuncia em diferentes línguas de forma singular, convocando o outro, pelo efeito que seu lugar de enunciação provoca.

Tomamos o conceito de enunciação a partir Benveniste (2006, p. 82): "colocar em funcionamento a língua por um ato individual de utilização".

$\mathrm{O}$ ato individual pelo qual se utiliza a língua introduz em primeiro lugar o locutor como parâmetro nas condições necessárias da enunciação. Antes da enunciação, a língua não é senão possibilidade da língua. Depois da enunciação, a língua é efetuada em uma instância de discurso, que emana de um locutor forma sonora que atinge um ouvinte e que suscita uma outra enunciação de retorno. (BENVENISTE, 2006, p. 83). 
$\mathrm{Na}$ interdependência do discurso, o locutor que se apresenta como "eu" e se dirige a um alocutor, um "tu". Assim, nessa conjuntura de reciprocidade, nenhuma das pessoas se concebe sem o outro, apenas se complementam e se revezam, pois “a razão da 'fala' do sujeito não é que ele disponha de uma linguagem, mas de que esta responda por uma oscilação entre o engano e o não engano introduzido pela relação com o outro" (JERUSALINSKY, 2008, p. 140).

A organização da linguagem permite aos locutores que se apropriem da língua, cada um ao seu tempo, para designarem-se como "eu". E esse "eu" é o centro de referência da enunciação e presta-se à função de base da constituição do tempo e espaço no discurso.

Todavia, para que a linguagem se transforme em discurso, é essencial que se tenha noção da categoria de pessoa que, segundo Flores (2009), deve ser entendida como um par linguístico, que só existe uma em detrimento da outra,

... é indissociável porque não há como enunciar eu sem prever tu, ainda que este tenha existência imaginada ou mesmo, no monólogo, seja desdobramento do próprio eu; é reversível uma vez que tu pode tornar-se eu pela tomada da palavra; é, a cada vez, único, entendendose unicidade como ausência de repetição e de pluralização; é opositivo à não-pessoa-ele. (FLORES, 2009, p. 186-187, grifo do autor).

Em uma situação de apropriação linguística, os interlocutores se revezam nos lugares do 'eu' e do 'tu', constituindo-se simultaneamente como sujeitos da enunciação. "Cada enunciação é um ato que serve o propósito direto de unir o ouvinte ao locutor por algum laço de sentimento, social ou de outro tipo" (BENVENISTE, 2006, p. 90). 
Recorte Enunciativo 3:

Contexto: A criança estava sentada no sofá brincando de videogame na presença de familiares.

\begin{tabular}{|c|c|c|c|c|}
\hline & Avó alemã & Mãe & Criança & Cena enunciativa \\
\hline 1 & & $\begin{array}{l}\text { João, o que cê tá } \\
\text { fazendo? }\end{array}$ & & $\begin{array}{l}\text { A criança estava } \\
\text { movimentando o } \\
\text { volante do } \\
\text { videogame de um } \\
\text { lado para o outro, } \\
\text { quando a mãe a } \\
\text { questiona usando a } \\
\text { língua portuguesa. }\end{array}$ \\
\hline 2 & & & & $\begin{array}{l}\text { A criança fica em } \\
\text { silêncio por volta } \\
\text { de } 40 \text { segundos. }\end{array}$ \\
\hline 3 & $\begin{array}{l}\text { Sagt deine Mutter, } \\
\text { was wir tu! } \\
\text { (Fala para sua } \\
\text { mãe o que nós } \\
\text { estamos } \\
\text { fazendo) }\end{array}$ & & & $\begin{array}{l}\text { A avó paterna fala } \\
\text { em dialeto } \\
\text { Schwäbisch e sorri } \\
\text { em conjunto com a } \\
\text { mãe da criança. }\end{array}$ \\
\hline 4 & & & $\begin{array}{l}\text { Ti ti ti ti ti } \\
\text { (sem } \\
\text { tradução) } \\
\text { Audi Carro }\end{array}$ & $\begin{array}{l}\text { A criança responde } \\
\text { rangendo os dentes } \\
\text { sem ritmo aparente. } \\
\text { Depois de } 10 \\
\text { segundos menciona } \\
\text { a marca do carro: } \\
\text { "Audi”, comum na } \\
\text { região em que a } \\
\text { criança reside. }\end{array}$ \\
\hline
\end{tabular}

Embora a resposta da criança ao questionamento materno não aconteça imediatamente e sofra interferência do discurso da avó paterna alemã, percebemos, no recorte anterior, a singularidade do sujeito multilíngue a partir da observação de sua enunciação em língua portuguesa (linha 4), ao mencionar a palavra 'carro' unida a palavra 'Audi (marca de carro alemã), após um enunciado da avó proferido em dialeto Schwäbisch (linha 3). 
A hesitação infantil (linha 2), talvez resultante da instabilidade do terreno movediço do estar entre línguas, no qual o sujeito não habita, mas é habitado por diferentes sistemas linguísticos, parece provocar efeitos de fala sobre o outro, que é interpelado pela ausência da língua e levado a reconfigurar o dizer sobre novo aporte linguístico: o dialeto (linhas 2 e 3).

"Qualquer pessoa pode fabricar uma língua, mas ela não existe, no sentido o mais literal, desde que não haja dois indivíduos que possam manejála como nativos. Uma língua é primeiro um consenso coletivo" (BENVENISTE, 2006, p. 20). Desse modo, não há possibilidade do sujeito entre-línguas reconfigurar os sistemas e criar uma nova língua: pode haver uma instabilidade no dizer causadora de estranhamentos. A língua é um sistema que se manifesta na enunciação, sendo a única atualização da comunicação intersubjetiva (FLORES, 2009, p. 150).

O recorte anterior apresenta o retrato enunciativo da criança que, ora se enuncia nas duas línguas em questão, portuguesa e alemã clássica, ora em dialeto Schwäbisch, quando em contato com habitantes da vila onde mora.

\section{Conclusão}

Ao longo deste artigo, procuramos apresentar a língua como lugar enunciativo de um sujeito diagnosticado com a Síndrome do X-Frágil destacando o universo contemporâneo da língua portuguesa. Semelhante ao que afirma Eckert-Hoff e Coracini (2010), citando Scherer, nos referimos ao lugar discursivo, por entendermos o sujeito como aquele que se constitui nos deslizes, na errância da língua, nas diversas identificações.

Nossas discussões percorreram o caminho do encontro do sujeito com as chamadas língua mãe, língua nacional e língua estrangeira, num contexto entre-línguas. Os recortes enunciativos apresentados ilustraram as discussões em torno da apropriação da língua, identidade e contemporaneidade.

Em cada momento que a criança fala há, inevitavelmente, exposição da apropriação do sistema linguístico a seu modo. $\mathrm{O}$ ato de capturar e se apropriar dos signos linguísticos, colocando-os em uso de modo particular, caracterizando, assim, a enunciação de que trata Benveniste (2006), apresenta o sujeito com Síndrome do X-Frágil como aquele que se enuncia mesmo que 
de forma fragmentada no terreno entre-línguas. "A língua de equívocos da contemporaneidade é desejo, mas também fuga de sentidos, que escapam do controle do sujeito, educado por corpo, mas sujeito a desordens e falhas" (DANTAS, 2012, p. 38).

São através de fatos, das vivências, dos vocábulos guardados na memória, que provocam efeitos e constituem identidade. Esta marca de identificação com o sujeito originária na relação com o sistema linguístico permite que essa ou aquela língua ganhe força em seu processo de apropriação pelo falante.

No ambiente entre-línguas, a enunciação do sujeito com X-Frágil deste estudo passa por um ato de identificação na/pela língua. $\mathrm{O}$ alemão clássico (Hochdeutsch), ensinado na escola, parece não ter encontrado terreno seguro para apropriação, sendo carregado de artificialidade e automatismo, o que torna a língua oficial da Alemanha não familiar.

Mesmo ocorrendo incômodo e estranheza, marcadas pelos momentos de silêncio e hesitação, enunciar-se na/pela língua portuguesa carrega em seu bojo histórias passadas que constituem o sujeito. A língua portuguesa é aquela que não quer silenciar, que teima em voltar. Esse retorno à língua portuguesa reafirma a ligação com a língua e a impossibilidade de substituí-la.

Arriscamos a pensar o estranho como familiar, que retorna e emerge pelos furos da língua e do sujeito (estruturas marcadas pela falta). Sujeito este que se viu obrigado a sufocar sua língua familiar e foi colocado diante de uma língua com poucos traços de parentescos com o português. Defender que a identificação subjetiva com uma língua permite sua apropriação, possibilita à criança deslizar seu discurso pelo dialeto Schwäbisch.

O sujeito entre-línguas se deflagra, sem moradia, eternamente exilado do território que não era o mesmo habitado pela língua. Por vezes a língua materna parece ser uma língua estranha e, por outras, o sujeito passa a ser um estrangeiro na própria língua. Portanto, a vivência de ser/estar entre línguas nas quais a criança com X-Frágil deste estudo está inscrita a coloca, inevitavelmente, em situação constante de confusão de línguas, controle do falar correto, de conflito de resistência ou de aceitação da língua do outro. O mesmo ocorre com um sujeito aprendiz de uma nova língua em situação 
escolar. Articular o contexto e a subjetividade com os conteúdos escolares são os maiores desafios colocados pela contemporaneidade.

Se, por um lado, a Síndrome do X-Frágil parecia ser um agravante à inscrição do sujeito na língua estrangeira, por outro, a identificação com um dialeto aproximou e permitiu à criança falar de um outro lugar, provocou efeitos e contribuiu na constituição do sujeito.

\section{Referências}

AUTHIER-REVUZ, J. Palavras incertas: as não-coincidências do dizer. Campinas: UNICAMP, 1998.

BENVENISTE, E. Problemas de linguística geral I. 5. ed. Tradução Maria da Glória Novak; Maria Luisa Neri. Campinas: Pontes, 2005.

BENVENISTE, E. Problemas de linguística geral II. 2. ed. Tradução Eduardo Guimarães et al. Campinas: Pontes, 2006.

BORTOLOTTO, H.; FREIRE, R. M. A. C.; SILVA, G. G. da. Sintomas de linguagem e síndrome de X frágil: estudo de caso. Distúrbios da Comunicação, São Paulo, v. 21, n. 3, p. 303-314, 2009.

BRAZÃO, M. L. Os rastros da lingua materna. 2010. Dissertação (Mestrado em Estudos Linguísticos) - Universidade Federal de Uberlândia, Uberlândia.

DANTAS, A. M. A língua e suas falhas: o discurso na contemporaneidade. Revista Leitura. Maceió, n. 50, p. 17-40, jul./dez. 2012.

DERRIDA, J. O monolinguismo do outro: ou a prótese de origem. Tradução F. Bernardo. Porto: Campo das Letras, 2001.

DIAMENT, A.; CYPEL, S. Neurologia infantil. 4. ed. Lefévre: Atheneu, 1996.

ECKERT-HOFF, B.; CORACINI, M. J. (Org.) Escrit(ur) a de si e alteridade no espaço papel-tela: alfabetização, formação de professores, línguas materna e estrangeira. Campinas: Mercado de Letras, 2010. 
FINK, B.; O sujeito lacaniano: entre a linguagem e o gozo. Rio de Janeiro: Jorge Zahar, 1998.

FISCH, G.; HOLDEN, J.; CARPENTER, N. Age related language characteristics of children and adolescents with fragile X syndrome. American Journal of Medical Genetics, v. 83, p. 253-256, 1999.

FLORES, V. N. (Org.). Dicionário de linguística da enunciação. São Paulo: Contexto, 2009.

GIACHETI, C. M.; COSTA, A. R.; SPINELLI, M. Achados fonoaudiológicos em indivíduos com a sindrome do cromossomo X frágil. São Paulo: Escola Paulista de Medicina, 1992.

GOLDGRUB, F. W. A máquina do fantasma: aquisição de linguagem e constituição do sujeito. São Paulo: Samizdat, 2008.

GUERREIRO, M. M. (Org.). Síndrome do X frágil: características clínicas, eletrencefalográficas e de imagem. Arquivos de Neuropsiquiatria, v. 56, p. 18-23, 1998.

HALL, S. A identidade cultural na pós-modernidade. Rio de Janeiro: DP\&A, 1992.

HARGEMAN, R. J.; HARGEMAN, P. J. Fragile X syndrome: diagnosis, treatment and research. 3. ed. Baltimore: The Johns Hopkins University Press, 2002.

JERUSALINSKY, A. Saber falar: como se adquire a língua? Petrópolis: Vozes, 2008.

LEFFA, V. J.; IRALA, V. B. O ensino de outra(s) língua(s) na contemporaneidade: questões conceituais e metodológicas. In: LEFFA, V. J.; IRALA, V. B. (Org.). Uma espiadinha na sala de aula: ensinando línguas adicionais no Brasil. Pelotas: Educat, 2014. p. 21-48.

LIER-DEVITTO, M. F. Falas sintomáticas: fora do tempo, fora do lugar. Cadernos de Estudos Lingüísticos, Campinas, n. 47, 2005.

LOPES, E. A identidade e a diferença. São Paulo: Edusp, 1997. 
MELMAN, C. Imigrantes: incidências subjetivas das mudanças de língua e país. Tradução Roseana Pereira. São Paulo: Escuta, 1992.

MOLINA, M. P. R; JUSTE, P.; FUENTES, R. F. J. Síndrome de X frágil. Dpto. Pediatría y Fisiologia, Facultad de Medicina, Universidad de Zaragoza, v. 1, p. 85-90, 2010.

MONTENEGRO, C. C. Sindrome X frágil. Inglaterra: Lulu.com, 2011.

MORAES, M. R. S. Materna/estrangeira: o que Freud fez da língua. 1999. Tese (Doutorado em Linguística) - Universidade Estadual de Campinas, Campinas.

SAUSSURE, F. Curso de linguistica geral. 28. ed. Tradução Antonio Chelini; José Paulo Paes; Izidoro Blikstein. São Paulo: Cultrix, 2012.

SCARPA, E. M. O lugar da holófrase nos estudos de aquisição da linguagem. Cadernos de Estudos Lingüisticos, Campinas, v. 51, n. 2, p. 187-200, 2009.

SCHWARTZMANN, J. S. et al. Autismo infantil. São Paulo: Memnon, 1995.

SILVA, C. L. A criança na linguagem: enunciação e aquisição. Campinas: Pontes, 2009.

SILVA, S. A. As interferências subjetivas da lingua materna no processo de aquisição da lingua francesa: entre a captura e a resistência. 2012. Dissertação (Mestrado em Ciências da Linguagem) - Universidade Católica de Pernambuco, Recife.

UYENO, E. Y; CAVALLARI, J. S. (Org.). Bilinguismos: subjetivação e identificações nas/pelas línguas maternas e estrangeiras. v. 9. Campinas: Pontes, 2011.

VEREZA, S. C. Quem fala por mim?: identidade na produção discursiva em língua estrangeira. In: MOITA LOPES, L. P.; BASTOS, L. C. (Org.). Identidades: recorte multi e interdisciplinares. Campinas: Mercado de Letras, 2002. p. 351-361. 
ZIMMER, M.; FINGER, I.; SCHERER, L. Do bilingüismo ao multilingüismo: intersecções entre a psicolingüística e a neurolingüística. ReVEL, v. 6, n. 11, p. 1-28, ago. 2008.

Recebido em: 02/09/2015 Aceito: $22 / 02 / 2016$ 